\title{
DIMINISHED PHENYLKETONURIA IN PHENYLPYRUVIC OLIGOPHRENIA AFTER ADMINISTRATION OF L-GLUTAMINE, L-GLUTAMATE OR L-ASPARAGINE ${ }^{1}$
}

\author{
By ALTON MEISTER,2 SIDNEY UDENFRIEND, AND SAMUEL P. BESSMAN

\begin{abstract}
(From the Laboratory of Biochemistry, National Cancer Institute, the Laboratory of Chemical
Pharmacology, National Heart Institute, National Institutes of Health, and the Department of Pediatrics, University of Maryland Medical School, Baltimore, Md.)
\end{abstract}

(Submitted for publication December 27, 1955; accepted February 9, 1956)

It is well known that patients with phenylpyruvic oligophrenia excrete large amounts of phenylpyruvic acid, phenyllactic acid, and phenylalanine in the urine, and that they also exhibit an unusually high blood level of phenylalanine $(1-4)$. That such patients also exhibit a markedly reduced capacity to convert phenylalanine to tyrosine was indicated by several investigations $(2,5,6)$ and was proven conclusively by isotopic study (7). It has been suggested that failure to catalyze this reaction is the basic metabolic defect in this disorder $(6,7)$. According to this interpretation, phenylalanine accumulates, and is converted to phenylpyruvic acid and other products in greater than normal quantities. The finding of abnormally high concentrations of phenylacetylglutamine in the urine of patients with phenylpyruvic oligophrenia $(8,9)$ is also consistent with the increased accumulation of phenylalanine, with its conversion to phenylpyruvic acid, and transformation of the latter compound to phenylacetic acid. In man the latter compound is excreted in the urine as phenylacetylglutamine $(10-12)$. It is reasonable to assume that the chemical defect is responsible in some way for the mental retardation of these patients; such an interpretation gains support from the observation that some patients appear to show improvement when the dietary phenylalanine intake is restricted (13-16).

It seems probable that the conversion of phenylalanine to phenylpyruvic acid takes place by transamination; this mechanism has been shown to be responsible for the analogous conversion of tyrosine to p-hydroxyphenylpyruvic acid (17-19). Such a transamination reaction would be expected to be reversible, so that in the presence of in-

\footnotetext{
1 Aided by a grant from the Playtex Park Foundation.

2 Present address : Department of Biochemistry, Tufts University School of Medicine, Boston, Mass.
}

creased concentrations of an appropriate amino group donor, less phenylpyruvic acid might be formed. We have therefore attempted to determine whether an appreciable decrease in the excretion of phenylpyruvic acid could be effected by administration of amino acids, such as glutamine, asparagine, and glutamic acid, which are known to be active in in vitro transamination systems (20, 21). Although it was not our major purpose to investigate amino acid administration as a possible therapeutic measure, it should be pointed out that reduction of phenylpyruvic acid formation (even if accompanied by an increase in phenylalanine concentration) might be a desirable result inasmuch as there is no evidence that phenylalanine per se is toxic ; ${ }^{3}$ phenylacetic acid, which is probably formed from phenylalanine, is known to be toxic to the central nervous system (23). It may be noted that several other unusual metabolites of phenylalanine have been found in the urine of patients with phenylketonuria $(24,25)$.

The present studies were also undertaken partly in an attempt to evaluate the possible involvement of glutamine in this disorder. The significance of glutamine and glutamic acid in brain metabolism has been emphasized by a number of investigations $(26,27)$, and these amino acids are also known to be widely distributed in other animal tissues; glutamine is a prominent constituent of human blood accounting for about one-fifth of the total amino nitrogen. The increased excretion of phenylacetylglutamine in phenylpyruvic oligo-

\footnotetext{
3 It has been found that the tyrosinase activity of mushrooms is competitively inhibited by high concentrations of phenylalanine (22); this observation suggests a mechanism for the possible toxicity of phenylalanine. In this connection, it is interesting to note that certain phenylketonuric patients who received a diet low in phenylalanine for several months exhibited a darkening of the hair and skin (13-16).
} 
phrenia might possibly result in a drain of body (and brain) glutamine.

The general plan in the present study was to administer a single dose of a given amino acid, after post-absorptive base-line values had been obtained; the effect of the administered amino acid on the excretion of phenylpyruvic acid and related compounds was followed for several hours. A significant result of these experiments was the observation that administration of glutamine, glutamic acid, or asparagine resulted in a marked reduction in the excretion of phenylpyruvic and phenyllactic acids. On the other hand, there was no demonstrable change in the excretion of phenylacetylglutamine after glutamine administration.

\section{METHODS}

The patients studied were two siblings, patient $C$, an 8-year-old girl weighing 18 kilograms, and patient $\mathrm{J}$, a 7-year-old boy weighing 13 kilograms. Both patients were imbeciles and were known to have excreted large quantities of urinary phenylpyruvic acid for several years. Physical development was normal, and at the time of these studies, they appeared free of other disease. These are the same patients studied previously by Udenfriend and Bessman (7).

The procedure employed in these experiments was as follows: No food was permitted after 8 p.m. on the night prior to the experiment, and urine was collected (by means of an indwelling catheter) at hourly intervals beginning at 3 or $4 \mathrm{a} . \mathrm{m}$. on the following day. At 8 or 9 a.m., the test substance in a dose of $7.6 \mathrm{mM}$ per kilogram of body weight was administered orally or by gastric tube, and urine collections were continued for 6 to 8 hours. Venous blood was drawn by femoral puncture just prior to administration of the test substance and at hourly intervals thereafter. The test substances were given by gastric tube to patient $\mathrm{J}$; in two experiments (Figures 3 (c) and 5). Patient $\mathrm{C}$ also received the test compound by gastric tube. Two or three such studies were performed on each patient per week.

Analytical procedures. Phenylpyruvic acid was determined by the procedures of Penrose and Quastel (28) and of Berry and Woolf (29), the latter being more reliable for samples containing relatively low concentrations of phenylpyruvic acid. $\alpha$-Ketoglutaric acid was determined by densitometric measurement $(30)$ of the corresponding 2,4-dinitrophenylhydrazone after separation from interfering hydrazones by paper chromatography (31). Phenyllactic acid was determined as described by Prescott, Borek, Brecher, and Waelsch (32) after destruction of the phenylpyruvic acid with hydrogen peroxide. In the latter step, the residue, after evaporation of the ether was taken up in $1 \mathrm{ml}$. of water and treated with $1 \mathrm{ml}$. of 6 per cent hydrogen peroxide at $37^{\circ}$ for 30 minutes. The excess peroxide was decomposed by addition of
$0.05 \mathrm{ml}$. of a crystalline beef liver catalase solution. Control and recovery studies indicated that peroxide treatment removed all of the keto acid without destroying phenyllactic acid. Phenylacetylglutamine was determined (cf. Woolf [8]) as follows: To a 5-ml. sample of urine was added $0.2 \mathrm{ml}$. of $6 \mathrm{~N}$ hydrochloric acid and $1.7 \mathrm{gm}$. of sodium chloride and the mixture was extracted four times with $20 \mathrm{ml}$. of ethyl acetate. The ethyl acetate fractions were dried over anhydrous sodium sulfate and evaporated; the residue was taken up in $5 \mathrm{ml}$. of $2 \mathrm{~N}$ hydrochloric acid and placed in an autoclave (15 lbs.' pressure) for one hour. The resulting solution was neutralized and analyzed for glutamate with glutamic acid decarboxylase (33). The recovery of glutamate from known solutions of phenylacetylglutamine in water or urine was 85 to 95 per cent. Phenylalanine was determined by the method

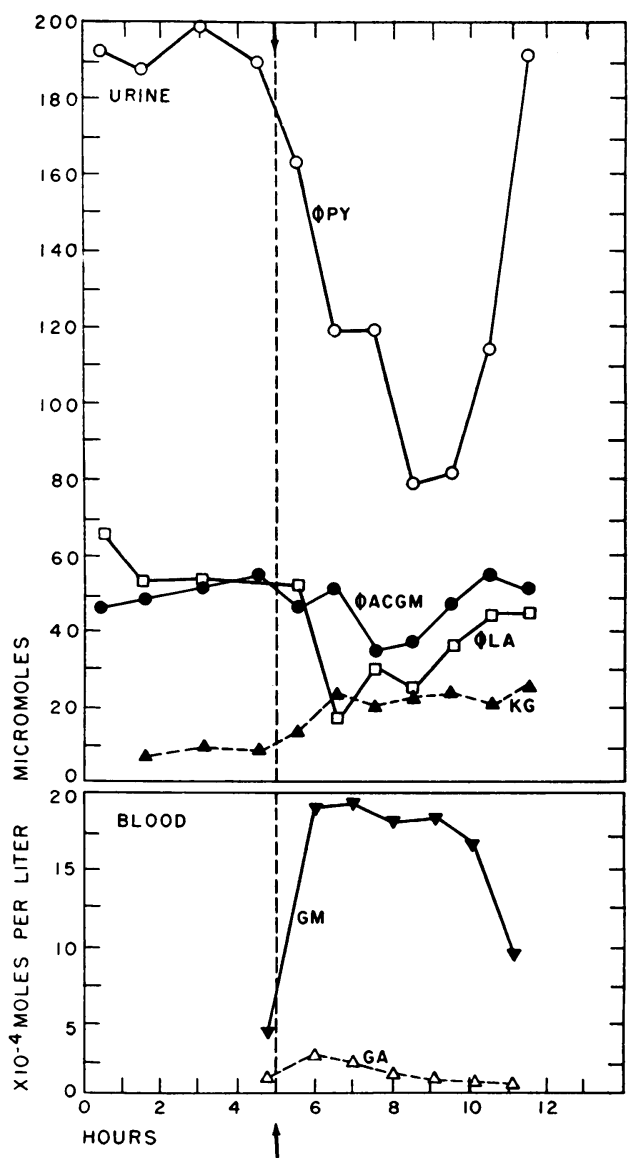

Fig. 1. Effect of Administration of L-Glutamine on Urinary Excretion of Phenylpyruvic Acid $(\phi P y)$, Phenylacetylglutamine ( $\phi$ ACGM), Phenyllactic Acid ( $\phi$ LA), ANd $\alpha$-Ketoglutaric Acid (KG), ANd on the Blood Levels of Glutamine (GM) and Glutamic ACID (GA)

A dose of $137 \mathrm{mM}$ of L-glutamine $(7.6 \mathrm{mM}$ per kilogram) was administered at the time indicated by the arrow (Patient $\mathrm{C}$ ). 


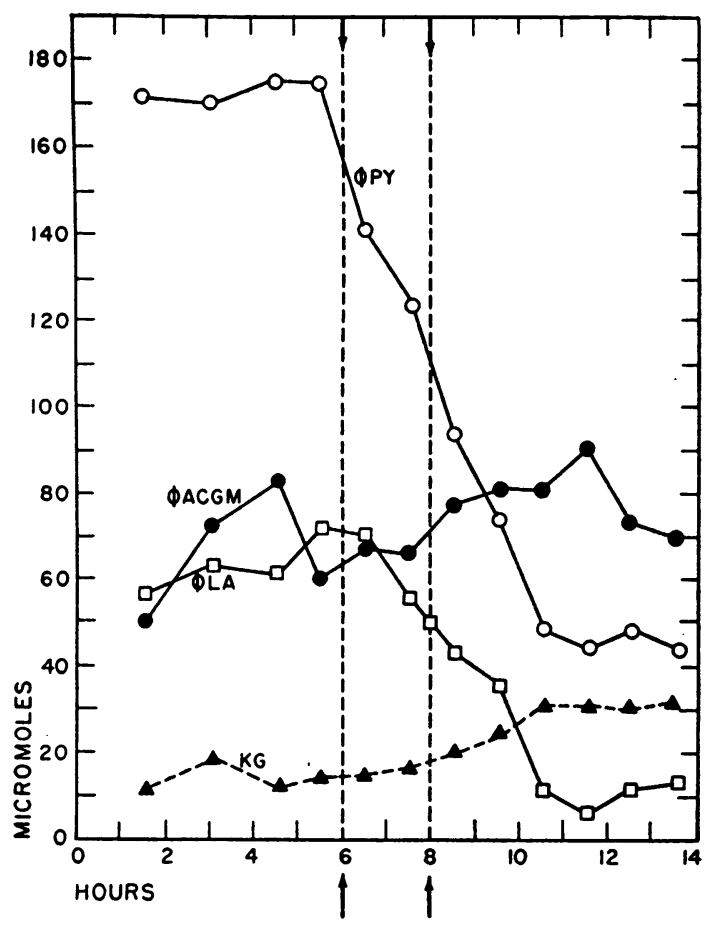

Fig. 2. Effect of Two Doses, EAch $7.6 \mathrm{MM}$ PER Kilogram of Body Weight, of L-Glutamine on Urinary Excretion of Phenylpyruvic Acid ( $\phi$ Py), Phenylacetylglutamine ( $\phi$ ACGM), Phenyllactic Acid ( $\phi$ LA) and $\alpha$-Ketoglutaric Acid (KG) Patient C

of Udenfriend and Cooper (34). Blood levels of glutamate and glutamine were determined as described by Bessman, Magnes, Schwerin, and Waelsch (35), and aspartate and asparagine by a method to be reported (36).

The amino acids used were analytically pure and were free of other amino acids as determined by paper chromatography.4 The L-glutamine was purified by passage through an anion exchange column (Amberlite IR 45) and by crystallization from water-ethanol; the product contained less than 0.1 per cent of glutamic acid as determined by enzymatic tests (37).

\section{RESULTS}

The effect of L-glutamine administration on the excretion of phenylpyruvic acid and related compounds is described in Figure 1. Within one hour after glutamine was given, the phenylpyruvic acid

4 The authors are indebted to Dr. Karl Pfister and Dr. Nathaniel Ritter of Merck and Company, and to Dr. B. Vassel and Dr. M. J. Blish of International Minerals and Chemical Corporation for generous amounts of L-glutamine and sodium L-glutamate. They also wish to thank Dr. Ruth Baldwin of the Department of Pediatrics, University of Maryland Medical School for the L-asparagine used in these investigations. excretion began to decrease, and a minimum excretion rate (about 40 per cent of the control value) was reached in about 4 hours; phenylpyruvic acid excretion returned to the control level in about 6 hours. The excretion of phenyllactic acid followed a similar pattern. On the other hand, the excretion of phenylacetylglutamine was not appreciably altered. The slight depression in excretion observed in this particular study during the third and fourth hours may not be experimentally significant, especially since such an effect was not observed in two other experiments. It is of interest that the excretion of $\alpha$-ketoglutaric acid increased about two-fold after glutamine administration. The five-fold increase in the blood level of glutamine suggests that a considerable proportion of this amino acid amide was absorbed as

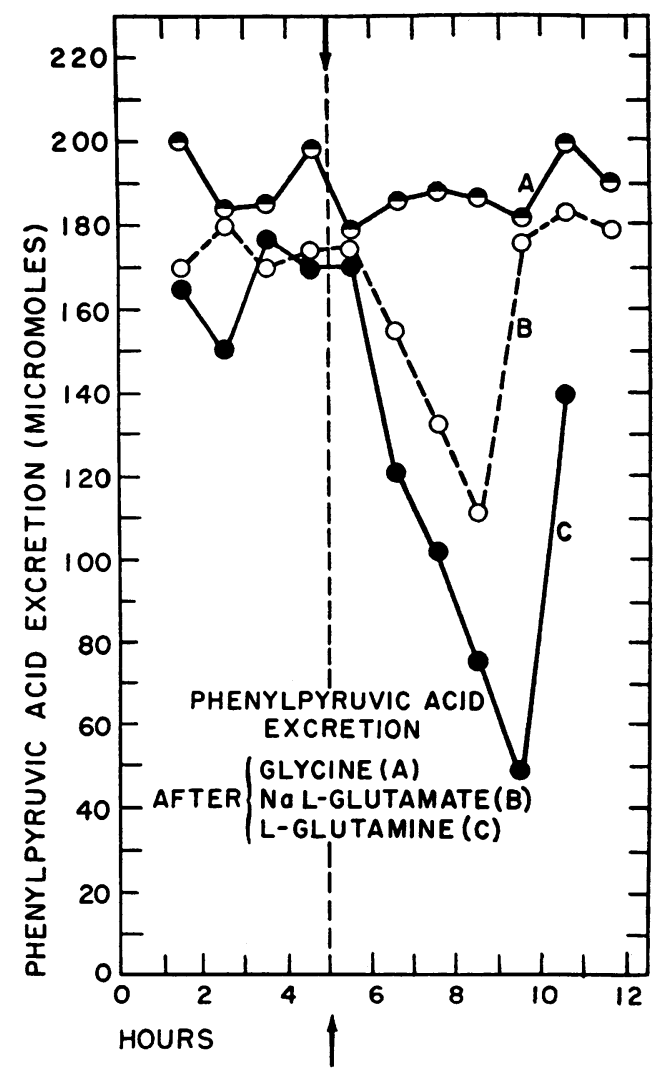

Fig. 3. Effect of L-Glutamine (Patient C), Sodium L-Glutamate (Patient J), and Glycine (PaTient C) ON URINARy Excretion of Phenylpyruvic ACID

The amino acids were administered in a single dose of $7.6 \mathrm{mM}$ per kilogram of body weight at the time indicated by the arrow. 
such, although the rise in blood glutamic acid is consistent with the occurrence of some deamidation. This suggests that glutamine is absorbed unchanged from the human intestine. Similar results have been reported in the cat (35). When two doses of glutamine were given (Figure 2), the results were similar, although the changes were more marked. In this experiment, the decrease in phenylpyruvic acid excretion was also prompt, reaching a value equivalent to approximately 23 per cent of the control level four hours after the initial dose. There was no return to the control level of excretion eight hours after the initial dose of glutamine was given. Again, a considerable reduction in phenyllactic acid excretion occurred, and about a two-fold increase in $\alpha$-ketoglutarate excretion was observed. There was no significant change in the excretion of phenylacetylglutamine.

Separate studies were carried out in which equi-

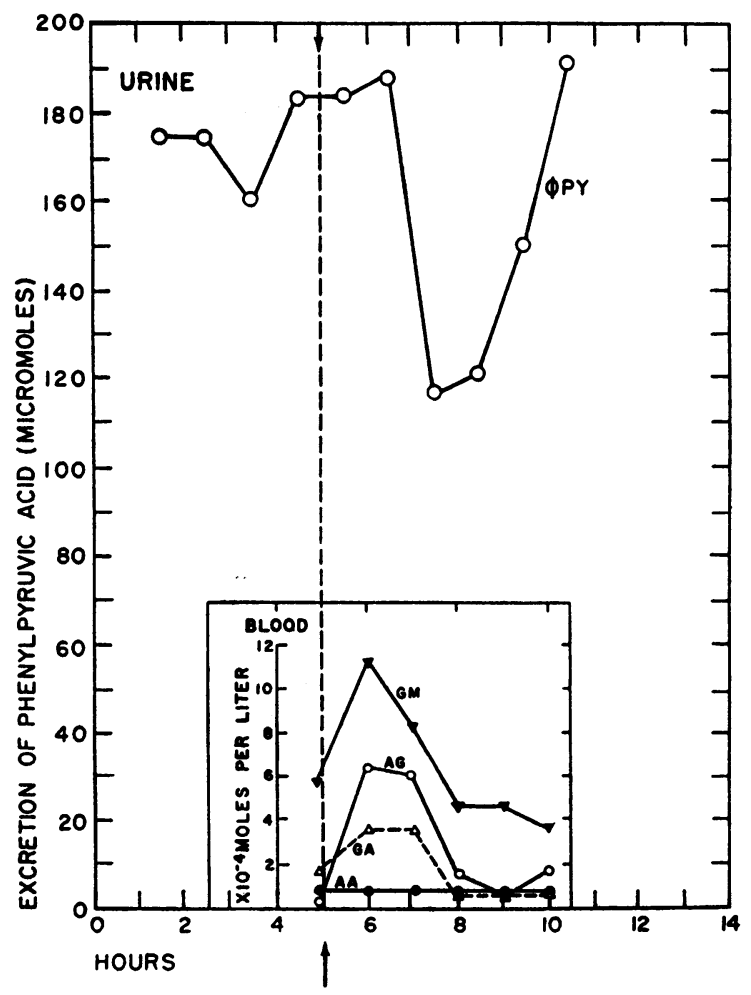

Fig. 4. Effect of Administration of L-Asparagine on the Urinary Excretion of Phenylpyruvic Acid ( $\phi$ Py) ANd Blood Levels of Asparagine (AG), Aspartic Acid (AA), Glutamine (GM), and Glutamic Acid (GA) (Patient J.)

A dose of $7.6 \mathrm{mM}$ of L-asparagine per kilogram of body weight was given at the time indicated by the arrow.

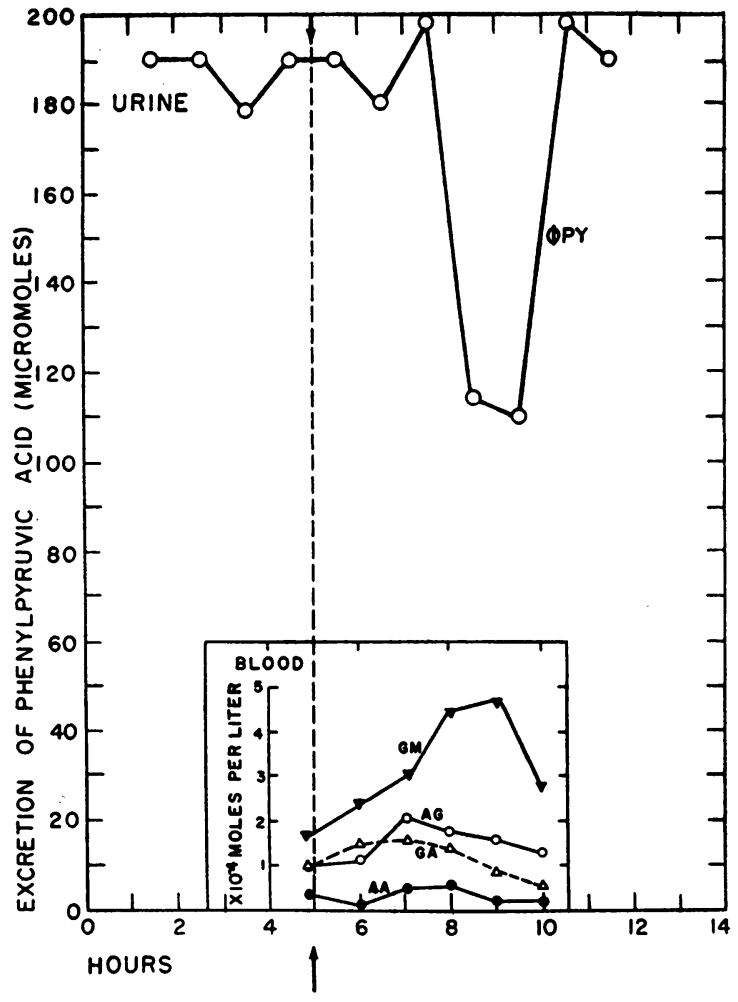

Fig. 5. Effect of L-Asparagine (Patient C)

See Figure 4, legend.

molar quantities of sodium L-glutamate, glycine, sodium succinate, and glucose were administered. Of these compounds, only sodium L-glutamate had a significant effect on phenylpyruvic acid excretion. A comparison of the results obtained in experiments in which sodium L-glutamate, glycine, and L-glutamine were administered is presented in Figure 3. The excretion fell to about one-third of the control level after glutamine administration, to about two-thirds of this value after glutamate was given, and no effect was observed with glycine. Phenylacetylglutamine excretion was not significantly affected by any of the amino acids.

Figures 4 and 5 summarize experiments in which L-asparagine was administered. As in the studies with glutamine and glutamate, there was a significant reduction of phenylpyruvic acid excretion. The level of excretion fell to 60 or 70 per cent of the control value. It is of some interest, however, that control levels of phenylpyruvic acid excretion were observed for the first 2 or 3 hours. This is in distinct contrast to the prompt decrease in excretion observed after glutamine and gluta- 
(1)

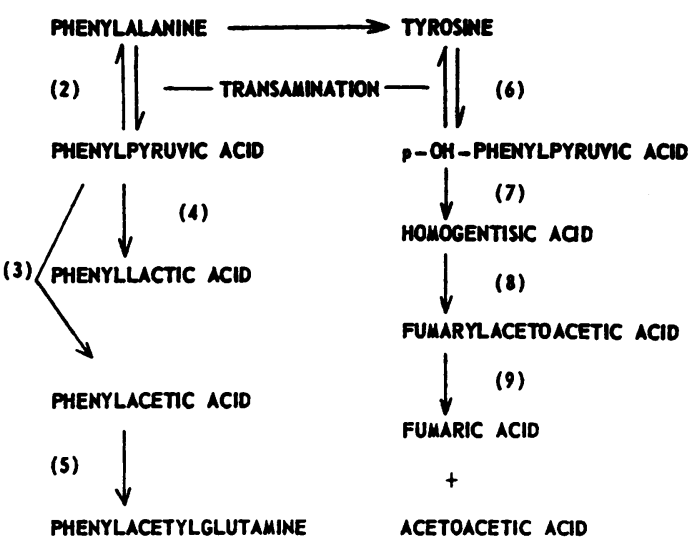

FIG. 6

mate administration (Figures 1 to 3 ). Also of interest is the observation that administration of asparagine (in both experiments) led to an appreciable rise of blood glutamine. In one experiment (Figure 4) the blood level of glutamine rose about two-fold, and in the other (Figure 5) about three-fold. There was also a moderate rise in the level of blood glutamic acid. Although there was a significant elevation of the blood level of asparagine after asparagine administration, this was not particularly marked in one experiment (Figure 5), and in neither experiment did the level of asparagine exceed that of glutamine. The blood aspartic acid levels did not significantly change in the course of these experiments. In none of the experiments was there a consistent elevation of the excretion or blood level of phenylalanine.

\section{DISCUSSION}

A marked reduction in the rate of conversion of phenylalanine to tyrosine (Figure 6, reaction [1] ) with consequent phenylalanine accumulation, would be expected to drive reaction (2) in the direction of phenylpyruvic acid formation. Reaction (2) : phenylalanine + keto acid $\rightleftharpoons$ phenylpyruvic acid + amino donor

Administration of glutamine, glutamate, or asparagine, by increasing the concentration of available amino donor would tend to force reaction (2) to the left. Although it is obviously difficult to interpret in vivo findings in terms of individual chemical reactions, the present observations appear at least consistent with such an explanation.
Phenyllactic acid probably arises by reduction of phenylpyruvic acid, and the observed decrease in excretion of this hydroxy acid may therefore be ascribed to the decrease in phenylpyruvic acid.

It might be anticipated, in accordance with reaction (2), that decreased formation of phenylpyruvic acid due to glutamine or glutamate administration, would be associated with an increase of $\alpha$-ketoglutaric acid and phenylalanine. Although an increase in $\alpha$-ketoglutarate excretion was observed in the studies with glutamine, no consistent elevation of the excretion of phenylalanine or of its blood level was observed. In one experiment there was a slight rise in the blood level of phenylalanine one hour after glutamine was given; however, this was not observed in other studies, and we are reluctant to conclude from our present data that the phenylalanine blood level has been demonstrated to increase. It is possible that an evanescent rise does indeed occur, but that the extra phenylalanine formed is rapidly diluted by the body fluids. Assuming that patient $\mathrm{C}$ has a total body fluid volume of 12 liters, and that a quantity of $120 \mu \mathrm{M}$ of phenylalanine (equivalent to the maximum total hourly deficit in phenylpyruvic acid excretion) is formed at one time, we have calculated that the blood level of phenylalanine would increase by only $1 \mu \mathrm{M}$ per $100 \mathrm{ml}$. This represents a change of less than 1 per cent in the blood level of phenylalanine, which is well within the range of experimental error of the procedure employed. Such a change would actually be expected to occur over a period of time which would make it even more difficult to detect. Any uptake of phenylalanine by cells would further minimize the rise in blood phenylalanine.

A decrease in phenylacetylglutamine excretion was not observed, even in association with a large reduction of phenylpyruvic acid excretion (Figure 2). Furthermore, the available data do not permit the conclusion that phenylacetylglutamine excretion increased significantly as a result of glutamine administration. This finding suggests that there is no deficiency of glutamine for the coupling reaction, and indicates that the observed decrease in phenylpyruvic acid excretion cannot be explained in terms of increased phenylacetylglutamine formation. The reason for the relatively constant rate of excretion of phenylacetylglutamine is not apparent; the mechanism of its formation, 
and the question of the formation of phenylacetic acid require further study.

Asparagine administration also produced a reduction of phenylpyruvic acid excretion; however, it is of interest that the decrease did not occur immediately following administration as in the case of glutamine and glutamate, but occurred after a lag of several hours. Furthermore, asparagine administration was associated with a considerable rise in the blood levels of glutamine and glutamate as well as in asparagine itself. The findings suggest that asparagine is rapidly metabolized and that its effect may be due to conversion to glutamine. It has been found in other studies (38), that administration of asparagine to normal children leads to increased blood levels of glutamine, without significant change of blood aspartate levels. An investigation of the apparent conversion of asparagine to glutamine would be desirable.

The greater effectiveness of glutamine as compared to glutamate in producing a decrease in the excretion of phenylpyruvic acid may be due to the participation of glutamine itself in transamination (20) or to the fact that glutamine may pass more readily through the cell membranes (cf. [26]). On the other hand, it is also possible that glutamate is the major active amino donor and that glutamine provides glutamate directly by deamidation and also by incorporation of its amide nitrogen into $\alpha$-ketoglutarate.

It may be concluded that the reduction of phenylpyruvic acid excretion following administration of glutamine, asparagine, or glutamate is consistent with, but does not prove, a transamination mechanism. There are a number of other lines of evidence also consistent with the occurrence of active transamination in vivo. These include the rapid incorporation of $\mathrm{N}^{15}$-amino acid nitrogen into almost all of the amino acids of the rat (39), and the ability of animals to grow on diets containing the $\alpha$-keto acid analogues of certain essential amino acids, $c f$. (21). It has also been observed that administration of glutamate to animals leads to an increase in the blood levels of $\alpha$-ketoglutarate and alanine, and a decrease in the blood level of pyruvate $(40,41)$.

The present findings appear to have significance in terms of the mechanism of the metabolic defect in phenylpyruvic oligophrenia. It appears unlikely that there is a serious loss of glutamine from the body in this disorder. The present suggestion as to the role of transamination in this disease may possibly have therapeutic implications. Although the administration of glutamic acid over a period of several weeks (and in conjunction with a regular diet) did not affect phenylketonuria (42), the possibility of administering large amounts of glutamine together with a diet low in phenylalanine should be considered. It has been suggested that urinary phenylpyruvate arises in the kidney (4), and it is probable that phenylpyruvate is formed by transamination in most of the other tissues of the body, cf. (21). It is known that circulating glutamine promptly reaches the tissues (including the brain [43]); maintenance of a sufficiently high tissue concentration of glutamine might serve to reduce phenylpyruvate formation in the brain and other tissues. The present findings suggest that glutamine lowers phenylpyruvate formation in the kidney, and are entirely consistent with a similar effect in other tissues. The greater availability of glutamine in recent months at relatively low cost may make feasible a long-term investigation of this problem.

\section{SUMMARY}

1. Two phenylketonuric patients were given single oral doses of L-glutamine, sodium L-glutamate, L-asparagine, glycine, sodium succinate or D-glucose, and the urinary excretion of phenylpyruvic acid was measured for several hours prior to and after administration of the test compound.

2. After glutamine was given, the excretion of phenylpyruvic and phenyllactic acids decreased to about one-third of the control level. Glutamate and asparagine also lowered phenylpyruvic acid excretion, although the effect was not as great as that observed with glutamine. No significant changes were observed in the excretion of phenylacetylglutamine or in the blood levels or urinary excretion of phenylalanine. The excretion of $\alpha$-ketoglutarate was increased after glutamine administration.

3. In contrast to the findings after glutamine and glutamate were given, the effect of asparagine on phenylpyruvic acid excretion occurred after a lag period. Since asparagine also led to increased blood levels of glutamine, it is possible that the effect of asparagine in lowering phenyl- 
pyruvic acid excretion is mediated through glutamine.

4. The results are discussed in terms of the concept that transamination plays a role in phenylpyruvic oligophrenia.

\section{ACKNOWLEDGMENT}

The authors wish to acknowledge the skillful technical assistance of Miss Patricia A. Abendschein, Mr. Samuel Seymour, Mr. Ennis C. Layne, and Mrs. P. Fraser Downey.

\section{REFERENCES}

1. Fölling, A., Uber Ausscheidung von Phenylbrenztraubensaure in den Harn als Stoff wechselanomalie in Verbindung mit Imbezillität. Ztschr. f. physiol. Chem., 1934, 227, 169.

2. Jervis, G. A., Block, R. J., Bolling, D., and Kanze, E., Chemical and metabolic studies on phenylalanine. II. The phenylalanine content of the blood and spinal fluid in phenylpyruvic oligophrenia. $\mathrm{J}$. Biol. Chem., 1940, 134, 105.

3. Jervis, G. A., Excretion of phenylalanine and derivatives in phenylpyruvic oligophrenia. Proc. Soc. Exper. Biol. \& Med., 1950, 75, 83.

4. Borek, E., Brecher, A., Jervis, G. A., and Waelsch, H., Oligophrenia phenylpyruvica. II. Constancy of the metabolic error. Proc. Soc. Exper. Biol. \& Med., 1950, 75, 86.

5. Jervis, G. A., Phenylpyruvic oligophrenia deficiency of phenylalanine-oxidizing system. Proc. Soc. Exper. Biol. \& Med., 1953, 82, 514.

6. Jervis, G. A., Studies on phenylpyruvic oligophrenia. The position of the metabolic error. J. Biol. Chem., 1947, 169, 651.

7. Udenfriend, S., and Bessman, S. P., The hydroxylation of phenylalanine and antipyrine in phenylpyruvic oligophrenia. J. Biol. Chem., 1953, 203, 961.

8. Woolf, L. I., Excretion of conjugated phenylacetic acid in phenylketonuria, Proc. Biochem. Soc. in Biochem. J., 1951, 49, ix.

9. Stein, W. H., Paladini, A. C., Hirs, C. H. W., and Moore, S., Phenylacetylglutamine as a constituent of normal human urine. J. Am. Chem. Soc., 1954, 76, 2848.

10. Thierfelder, H., and Sherwin, C. P., Phenylacetylglutamin, ein Stoffwechsel-Produkt des menschlichen Körpers nach Eingabe von Phenyl-essigsäure. Ber. d. deutsch. chem. Gesellsch., 1914, 47, 2630.

11. Sherwin, C. P., Comparative metabolism of certain aromatic acids. J. Biol. Chem., 1917, 31, 307.

12. Sherwin, C. P., Wolf, M., and Wolf, W., The maximum production of glutamine by the human body as measured by the output of phenylacetylglutamine. J. Biol. Chem., 1919, 37, 113.

13. Bickel, H., Gerrard, J., and Hickmans, E. M., The influence of phenylalanine intake on the chemistry and behavior of a phenylketonuric child. Acta Pediat., 1954, 43, 64.

14. Woolf, L. I., Griffiths, R., and Moncrieff, A., Treatment of phenylketonuria with a diet low in phenylalanine. Brit. Med. J., 1955, 1, 57.

15. Bickel, H., Gerrard, J., and Hickmans, E. M., Influence of phenylalanine intake on phenylketonuria. Lancet, 1953, ii, 812.

16. Armstrong, M. D., and Tyler, F. H., Studies on phenylketonuria. I. Restricted phenylalanine intake in phenylketonuria. J. Clin. Invest., 1955, 34, 565.

17. La Du, B. N., Jr., and Greenberg, D. M., The tyrosine oxidation system of liver. I. Extracts of rat liver acetone powder. J. Biol. Chem., 1951, 190, 245.

18. Schepartz, B., Transamination as a step in tyrosine metabolism. J. Biol. Chem., 1951, 193, 293.

19. Knox, W. E., and Le May-Knox, M., The oxidation in liver of L-tyrosine to acetoacetate through p-hydroxyphenylpyruvate and homogentisic acid. Biochem. J., 1951, 49, 686.

20. Meister, A., and Tice, S. V., Transamination from glutamine to $\alpha$-keto acids. J. Biol. Chem., 1950, 187, 173.

21. Meister, A., Transamination. Advances in Enzymology, 1955, 16, 185.

22. Dancis, J., and Balis, M. E., A possible mechanism for disturbance in tyrosine metabolism in phenylpyruvic oligophrenia. Pediatrics, 1955, 15, 63.

23. Sherwin, C. P., and Kennard, K. S., Toxicity of phenylacetic acid. J. Biol. Chem., 1919, 40, 259.

24. Boscott, R. J., and Bickel, H., Detection of some new abnormal metabolites in the urine of phenylketonuria. Scandinav. J. Clin. \& Lab. Invest., 1953, 5, 380.

25. Armstrong, M. D., and Robinson, K. S., On the excretion of indole derivatives in phenylketonuria. Arch. Biochem. \& Biophys., 1954, 52, 287.

26. Waelsch, H., Glutamic acid and cerebral function. Advances in Protein Chemistry, 1951, 6, 299.

27. Weil-Malherbe, H., Significance of glutamic acid for the metabolism of nervous tissue. Physiol. Rev., 1950, 30, 549.

28. Penrose, L., and Quastel, J. H., Metabolic studies in phenylketonuria. Biochem. J., 1937, 31, 266.

29. Berry, J. P., and Woolf, L. I., Estimation of phenylpyruvic acid. Nature, 1952, 169, 202.

30. Block, R. J., LeStrange, R., and Zweig, G., Paper Chromatography, a Laboratory Manual, New York, Academic Press, 1952.

31. Meister, A., and Abendschein, P. A., Chromatography of alpha keto acid 2,4-dinitrophenylhydrazones and their hydrogenation products. Anal. Chem., In press.

32. Prescott, B. A., Borek, E., Brecher, A., and Waelsch, H., Studies on oligophrenia phenylpyruvica. I. Microbiological determination of L- and D-phenylalanine and of phenyllactic acid. J. Biol. Chem., 1949, 181, 273. 
33. Meister, A., Sober, H. A., and Tice, S. V., Determination of aspartic and glutamic acids by enzymatic decarboxylation. J. Biol. Chem., 1951, 189, 591.

34. Udenfriend, S., and Cooper, J. R., Assay of L-phenylalanine as phenylethylamine after enzymatic decarboxylation; application to isotopic studies. J. Biol. Chem., 1953, 203, 953.

35. Bessman, S. P., Magnes, J., Schwerin, P., and Waelsch, H., The absorption of glutamic acid and glutamine. J. Biol. Chem., 1948, 175, 817.

36. Bessman, S. P., and Layne, F. L., A microdetermination of aspartic acid and asparagine. In preparation.

37. Levintow, L., and Meister, A., Reversibility of the enzymatic synthesis of glutamine. J. Biol. Chem., 1954, 209, 265.

38. Bessman, S. P., Unpublished observations.

39. Schoenheimer, R., The Dynamic State of Body Constituents, Cambridge, Harvard University Press, 1949.
40. Klingmüller, V., and Vogelesang, K. H., Untersuchungen über den Stoff wechsel der L (t) Glutaminsäure. I. Mitt. : Allgemeinwirkungen und Veränderungen des Blutchemismus, insbesondere des Gehalts an Ketosäuren im Plasma nach Verabreichung von $L(+)$ - Glutaminsäure in vivo. Ztschr. f. physiol. Chem., 1955, 300, 97.

41. Klingmüller, V., Gayer, J., and Bramstedt, F., Untersuchungen über den Stoff wechsel der L (+) - Glutaminsäure. II. Mitt.: Verschiebungen im Plasmaspiegel freier aminosäuren nach Glutaminsäuregaben. Ztschr. f. physiol. Chem., 1955, 300, 107.

42. Woolf, L. I., and Vulliamy, D. G., Phenylketonuria with a study of the effect upon it of glutamic acid. Arch. Dis. Childhood, 1951, 26, 487.

43. Schwerin, P., Bessman, S. P., and Waelsch, H., The uptake of glutamic acid and glutamine by brain and other tissues of the rat and mouse. J. Biol. Chem., 1950, 184, 37. 